Quinto Sol, № 1, pp. 41-74

\title{
REFLEXIONES SOBRE HISTORIA AGRARIA, REGIONAL Y COMPARADA: EL ARRENDAMIENTO DE TIERRAS DE AGRICULTURA CEREALERA EN LA COLONIA TARDÍA ${ }^{1 .}$
}

\section{Raúl O. FRADKIN •}

El desarrollo de las investigaciones en Historia Regional en nuestro pais permite que nos interroguemos acerca de las direcciones que estamos definiendo a través de nuestra práctica. Un repaso rápido de la producción de los últimos 10 años permite observar un conjunto de trabajos con alto grado de detalle y rigor documental pero, en perspectiva, puede presentarse la posibilidad de un cierto punto de saturación. ¿En qué sentido? Cubierta al menos en parte una fase de acumulación de información y de descripciones sólidamente fundamentadas se hace cada vez más necesario avanzar en explicaciones que puedan dar mejor cuenta de toda una gama de fenómenos comunes. En este sentido, nuestra historia regional afronta el desafío de encarar la generalización sin perder el "sabor" de las especificidades irrenunciables para el conocimiento histórico.

Los estudios regionales han permitido enfocar una serie de fenómenos y procesos y obtener una visión más realista de ellos. El efecto ha sido -sin duda- enriquecedor pero, al mismo tiempo, puede dar como resultado una especie de visión de historias en paralelo,

\footnotetext{
${ }^{1}$ Una primera versión de este trabajo fue presentada en el Simposio de Historia Regional realizado en las $V$ Jornadas Interescuelas/Departamentos de Historia y $1^{\text {a }}$ Jornadas efectuadas en Montevideo en octubre de 1995.

- UNLU-UBA
} 
poco conectadas entre sí. Es claro también que esa conexión no conviene buscarla en un enfoque que limite el estudio de lo regional a la verificación regional de "modelos generales", que se supone habrían de contener las explicaciones y convendría intentar otro tipo de aproximaciones. Todavía perduran modos de pensar nuestra historia como si hubiera niveles de jerarquía diferente en el status del conocimiento y la historia regional no puede ya ser pensada como si fuera una versión reducida de la historia "nacional". En este contexto parece afirmarse la necesidad de repensar mejor las demarcaciones que aceptamos como habituales y enfocar otro tipo de conexiones entre los diferentes ámbitos. En especial, una que hoy se presenta como un verdadero obstáculo es la tajante separación entre los estudios pampeanos y lo que a veces se ha denominado "extrapampeanos". Otra, hace a la periodización, pues superar la restricción habitual de los marcos temporales obligará a replantear los modos convencionales de periodización y a dotar a los análisis de una perspectiva temporal más larga y abarcadora.

Esta interrogación no puede hacerse sin considerar al menos dos cuestiones que nos enmarcan. Por un lado, las presiones más relevantes que cruzan el campo historiográfico en su conjunto. Por ejemplo, es saludable el intento fácilmente reconocible por renovar la práctica historiográfica atendiendo a los más nuevos aportes pero también es cierto que su inclusión no puede prescindir de la base de sustentación de la que se parte. Sería por cierto prematuro, por ejemplo, anunciar el agotamiento de la historia económica cuando todavía es demasiado lo que tiene para decir; o incluso, no convendría proclamar el fin de la necesidad de cuantificar una serie de fenómenos de los que todavía se carece de una medida más o menos fundada para sustituirlos por indagaciones exclusivamente cualitativas o por perspectivas restringidamente políticas o culturales. Del mismo modo, no se avanzaría haciendo un tipo de historia regional y económica que prescindiera de las perspectivas abiertas en otros campos y sobre todo, de explorar las posibilidades efectivas de una historia a las variadas dimensiones de lo social a la que se presta como pocas la historia regional.

Pero esta interrogación no puede realizarse sin efectuar un cierto reconocimiento de la herencia en la que nos sustentamos. Por cierto que la historia agraria ocupa un lugar especial dentro del campo de estudios regionales, una relación tan estrecha que lo a hecho su tributario más en un campo historiográfico que tuvo como referente de renovación primordial to que por comodidad y brevedad podemos llamar la escuela francesa. Si lo que estamos discutiendo es el futuro de este campo quizás sea conveniente 
recordar brevemente de donde venimos. Para ello apelaré a los resultados y a los problemas que debo afrontar en las dos líneas de investigación que vengo trabajando².

\section{Breve introducción historiográfica: historia regional, historia agraria e historia comparada.}

El campo de estudios de historia regional se ha constituido a partir del campo de estudios agrarios y, nuestra historia agraria y la latinoamericana en su conjunto, ha tenido una nota predominantemente francesa en su conformación. Aquí cabe traer a la memoria el libro de F. Chevalier de 1952, verdadero hito de la historia agraria latinoamericana y modelo interpretativo imperante durante dos décadas ${ }^{3}$. Si compartimos este diagnóstico quizá convenga detenerse un poco en el origen de la historia agraria y explorar mejor su relación con la historia regional y la historia comparada.

Para ello nada mejor que recordar brevemente las obras del historiador que sentó las bases de esta especialidad. Obviamente me refiero a Marc Bloch. Hacia 1924 aparece Les Rois thaumaturges, una verdadera exploración en la antropología histórica y la historia de las mentalidades organizada básicamente en torno a una comparación entre Francia e Inglaterra que no excluye otras más abarcadoras. Ya en esta obra es perceptible su preocupación por situar los fenómenos sociales que analiza en su propio contexto. La delimitación del contexto lo lleva a cuestionar el "marco nacional" para rescatar en cambio el valor de los contextos regionales sin escindirlos del europeo e, incluso, otros más amplios. En 1931 da a conocer su Les caracteres originaux de /historie rurale francaise, que puede considerarse el libro fundador de la historiografía rural contemporánea $y$, en muchos aspectos, una obra aún no igualada ni continuada en plenitud. En ella ya puede verse la estrecha relación entre estos campos historiográficos. Conviene considerar que allí resume artículos y conferencias previas, especialmente los dictados en el Instituto de Estudios Comparados de las Civilizaciones de Oslo. Bloch fue, sin duda, ante todo un

2 Por un lado, sobre el arrendamiento de tierras y las relaciones sociales en la campaña bonaerense de los siglos XVIII y XIX y, por otro, la investigación sobre historia comparada en conjunto con la Prof. Susana Murphy en la UNLu.

${ }^{3}$ F. CHEVALIER, La formación de los latifundios en México, México, FCE, 1976. No por nada tenía como dedicatoria "A la memoria de Marc Bloch cuyas lecciones me dieron la idea de este trabajo". 
historiador de las sociedades rurales que prefiere el cuadro regionai antes que el cronológico. Aquí la incidencia del comparativismo puede verse en toda su dimensión junto a una ampliación notable de la noción de lo rural, una atención decidida a los fenómenos de larga duración y un ejercicio sistemático de la comparación ${ }^{4}$. Su obra abrió el camino a los estudios monográficos, a los estudios regionales de historia rural que se transformaron en una de las fuerzas dominantes de la historiografía posterior ${ }^{5}$.

Mirada a largo plazo aquella contribución, es evidente que la ampliación de la noción de rural y la atención prestada a las duraciones han sido rasgos de la historia posterior pero, en cambio, la tercera -la perspectiva comparada- ha quedado diluída. Creo que en esta escisión de una obra pensada en conjunto residen las claves de algunos problemas posteriores, pues el comparativismo no era una adición aleatoria sino la trama misma de su razonamiento tanto en la investigación como en la exposición de los resultados. Lo mismo puede decirse de su tercera gran obra. En La Societé féodale (1939-40) estos elementos aparecen claramente combinados pero dotados de una perspectiva comparativa todavía más ambiciosa (que abre y cierra el libro) y una más clara impronta teórica en una evolución que fue para Duby un acercamiento al marxismo y que Febvre reprochó por "sociologismo". Sin duda la obra de Bloch ha terido gran predicamento posterior incluso fuera de Francia en la antropología social inglesa, en la historiografía alemana y en la microhistoria italiana. Pero ha quedado desgajada de la perspectiva comparativista que había mostrado recuperable para la historia y no como campo exclusivo de la sociología ${ }^{6}$.

Ello le da a Bloch un lugar específico en el movimiento de Annales. Pero también a su legado y a su recepción. En los libros clásicos que fundamentaron el campo de los estudios agrarios latinoamericanos coloniales todavía podía verse esta impronta aunque ya algo desdibujada $y$, a veces, bastante forzada. Luego, en cambio, durante la fase de gran expansión de estos estudios -de los años 60 a los 80 - puede reconocer que generalmente esta perspectiva o se ha perdido o tiene un lugar muy secundario. Porque este campo

${ }^{4}$ P. BURKE, La revolución historiográfica francesa. La escuela de los Annales: 19291989, Madrid, Gedisa, p.30.

${ }^{5}$ B. GEREMEK, Marc Bloch, historiador y resistente, Buenos Aires, Biblos, 1990, p. 1

6 H.G. HAUPT, "La lente émergence d'une historie comparée", en Passés Recomposés. Autrement, 150-151, Paris, Janvier 1995, pp.196-207. 
historiográfico es, más bien, acorde con la evolución post-Bloch de la historia rural francesa. De este modo, esta historia rural fue cada vez más una historia agraria netamente inscripta en lo que se llamó la "historia económica y social" hasta que ambos términos de la ecuación tendieron a escindirse. Tuvo entre sus impulsos básicos la atracción por la cuantificación y, en especial, de la historia de los precios impulsada primero por F. Simiand y, luego por E. Labrousse y G. Lefebvre durante las décadas de 1930 y 1940 . A elio siguió un detallado estudio de la producción, las técnicas, las formas de tenencia de la tierra y las estructuras sociales. El momento culminante de este movimiento hacia las estructuras y los ciclos que definían las coyunturas se verá en los 60 y 70 (P. Goubert, G. Duby, J. Meuvert, P. Vilar, E. Le Roy Ladurie, entre otros). Sin duda uno de sus resultados primordiales ha sido el reencuadre de la historia regional, la crisis del marco nacional para el estudio de las sociedades de antiguo régimen y medievales y el seguimiento de las fases de equilibrio y desequilibrio. $Y$ puede decirse que la historia demográfica es buena parte resultado de este movimiento y con ello, un enorme desafío que impactó muy fuertemente en el conjunto de la historia social.

¿Era la materialización en un programa de investigaciones seriales colectivas de fuerte rango regional del programa de Bloch? Sólo hasta cierto punto. Ante todo había perdido buena parte de la carga comparativista que tenía en él y convertido la aspiración de "totalidad" en una serie de estratos fijos primero que luego llevó a su casi completa separación y fragmentación.’ En todo caso, lo que me importa señalar es que de ello resulta un modelo historiográfico muy fuerte que opera en buena medida como referente básico de la historia regional: la proliferación de los estudios de casos predominante en los años 60 que definió todo un capítulo de la historiografía francesa $y$ un modo de producción historiográfico muy influyente en nuestro continente y en especial en el campo de los estudios agrarios. En consecuencia, si el impulso blochiano a una historia rural atenta a las condiciones regionales puede considerarse una línea de fuerza de la historiografía posterior, no sucedió lo mismo con la historia comparada. Y, en este sentido, las palabras de Bloch de 1928 resuenan plenas de actualidad:

"El método comparativo puede mucho: creo que su generalización y perfeccionamiento son una de las necesidades más urgentes que se imponen hoy a los estudios históricos [...] Es evidente, sin embargo, que la mayor parte de los historiadores

\footnotetext{
${ }^{7}$ Francois DOSSE, La historia en migajas. De "Annales" a la "nueva historia", Valencia, Edicions Alfons El Magnanim, 1988.
} 
no se convirtieron profundamente: opinan cortésmente del asunto vuelven a su tarea, sin cambiar para nada sus costumbres. ¿Por qué? Sin duda porque se les dejó creer con demasiada facilidad que la 'historia comparada' era un capítulo de la filosofía de la historia o de la sociología general, disciplinas que, según su talante, el trabajador ya venera, ya acoge con una sonrisa escéptica, pero que, de ordinario, evita practicar. Lo que se pide a un método es que sea un instrumento técnico, de uso corriente, manejable y susceptible de resultados positivos. El método comparativo es precisamente eso, pero no estoy seguro de que hasta aqui, se lo haya mostrado lo suficiente. Puede y debe ingresar en las investigaciones de detalle. Su futuro, el futuro, quizá, de nuestra ciencia debe pagar ese precio. ${ }^{\prime B}$ La cita pone en claro la perspectiva y, en especial, la relación que establece entre comparación, investigaciones de detalle y futuro de la historiografía. Me temo que estas palabras tienen demasiada vigencia.

Febvre había percibido el sentido de la concepción de su colega y a propósito de Les caracteres...observó: "señala el advenimiento de una historia rural que, mediando entre la historia de la técnicas agrícolas, la del régimen dominical y la de la evolución comparada de los pueblos europeos va a ser durante mucho tiempo uno de los campos de estudio más fecundos del ámbito histórico ${ }^{\prime \theta}$

Pero el pronóstico de Febvre a la edición francesa de 1932 sólo será en parte acertado, en el sentido del éxito indudable de la historia rural en la historiografía francesa posterior y por ese camino de la misma historia regional. No lo será en cambio en cuanto a la historia comparada. Pero la cita, sí tiene una utilidad, es que permite ver con precisión la inescindibilidad de entre estas tres variantes de un mismo enfoque histórico: lo rural, lo regional y lo comparado.

Junto a ello hay otro punto central en su enfoque: la concepción misma de lo agrario se ha ido transformado en estas décadas como resultado entre otros aspectos de la creciente especialización y la demarcación de una serie de campos cada vez más autónomos entre sí. De ese modo, se han desarrollado estudios que van desde una

\footnotetext{
${ }^{8}$ Marc BLOCH, "Por una historia comparada de las sociedades europeas", en G. Godoy y E. Hourcade: Marc Bloch. Una historia viva, Buenos Aires, CEAL, 1992, p.63. (el subrayado es mío).

9 L. FEBVRE: "Advertencia al lector", en M. BLOCH: La historia rural francesa. Caracteres originales, Barcelona, Crítica, 1978, p. 14.
} 
historia de la agricultura en sentido estricto hasta una historia global de la civilización rural. ${ }^{10}$ Pero los últimos años han visto un cierto retraimiento de la historia rural en Francia y especialmente un distanciamiento de sus dimensiones económicas. Frente a ello resulta de interés considerar el sentido que tienen hoy día las nuevas propuestas que pretenden recuperar terreno: en el editorial del primer número de Historie \& Société Rurales ${ }^{11}$ se propone la necesidad de trascender el aislamiento y sitúa la apertura al comparativismo. Estos movimientos de las ondas agitadas del mar historiográfico no conviene que nos pasen desapercibidos, especialmente en un campo historiográfico a veces proclive a pensar que la innovación puede pasar por alto la tradición del propio campo.

En nuestro país, el peso central de la historia rural ha recaido en la historia agraria, es decir un estudio que ha estado centrado ante todo en la producción agraria en el sentido más amplio. ${ }^{12}$ Sin embargo, al menos en el caso rioplatense, su mismo desarrollo está imponiendo la necesidad de atender a otros aspectos que hagan comprensible la vida social rural. En este sentido podemos afirmar que el campo de la historia agraria rioplatense hasta mediados del siglo XIX anuncia recientemente signos firmes de su conversión en una auténtica historia rural, una visión más abarcadora de múltiples dimensiones de análisis, no ya como agregado de niveles poco concertados entre sí sino como facetas inescindibles del fenómeno que se analiza. Se sitúa así -y seguramente sin proponérselo- como espacio de intersección y debate de varias perspectivas historiográficas. Se trata de un campo historiográfico que en tres lustros se ha renovado en extensión y profundidad hasta tal punto que puede decirse que recién ahora se ha integrado al campo de los estudios agrarios americanistas por preocupaciones, enfoques y estilos historiográficos ${ }^{13}$. La paradoja reside en que esta

10 C.F. SANTANA CARDOSO y H. PEREZ BRIGNOLI, Historia económica de América latina, Barcelona, Crítica, 1979, 1, pp. 11-14.

11 Ghislain BRUNEL y Jean-Marc MORICEAU: "Un renouveau pour I'historie rurale", 1, 1994, pp. 7-10.

12 J.C. GARAVAGuiA: "Historiografía de la historia agraria colonial", en Comité Internacional de Ciencias Históricas. Comité Argentino: Historiografía argentina (1958-1988). Una evaluación crítica de la producción historiográfica argentina, Buenos Aires, 1988.

13 R. FRADKIN, "La historia agraria y los estudios de establecimientos productivos en Hispanoamérica colonial: una mirada desde el Río de la Plata", en R. FRADKIN (comp.), La 
renovación lo está llevando cada vez más a una concepción de lo agrario cercana a la que proponía hace décadas Marc Bloch. ${ }^{14}$

\section{El fenómeno del arrendamiento en Buenos Aires y las fuentes disponibles.}

En esta ocasión nuestro interés está centrado en el arrendamiento de tierras para la agricultura cerealera en la colonia tardía. Cuando comenzamos nuestra investigación prácticamente no había estudios previos aunque las fuentes más conocidas eran muy locuaces al respecto: en ellas eran frecuentes las referencias a que, en buena medida, la agricultura tardocolonial estaba sustentada en torno al arrendamiento de la tierra. EI problema no pudo ni ser planteado como tal hasta que los estudios de Garavaglia pusieron de relieve la importancia de la agricultura. Ya en sus primeros trabajos llegó a postular que una importante proporción esta producción estaba en manos de campesinos arrendatarios -alrededor de un 35\%- y no es casual que ello haya sido observado por quien antes había trabajado intensamente sobre otros contextos regionales coloniales ${ }^{15}$. El desarrollo de la investigación hasta el momento me ha permitido obtener algunos resultados, abrir un haz de nuevas preguntas y enfrentar algunos problemas que son los que me interesa traer al debate ${ }^{16}$.

historia agraria del Río de la Plata colonial. Los establecimientos productivos, 1, Buenos Aires, CEAL, 1993, pp. 7-44.

${ }^{14}$ En BLOCH el término preferido era el de historia rural y su misma concepción de lo agrario asi lo evidencia: "¿Qué es, pues, el régimen agrario? Si nos inclinamos sobre un grupo rural determinado, un pequeña colectividad que vive en un territorio de mediana extensión, percibimos facilmente que toda su vida se halla regulada por un conjunto complejo a la vez de recetas técnicas y de costumbres jurídicas, que esas recetas técnicas y esas costumbres juridicas, en gran medida se conciben como impuestas. "M. BLOCH: "El problema de los regímenes agrarios", en G. GODOY y E. HOURCADE, ob. cit. p.109.

15 J.C. GARAVAGLIA, Economía, sociedad y regiones, Buenos Aires, Ediciones de La flor, 1987, p.42.

${ }^{16}$ Cf. Raúl FRADKIN: "Producción y arrendamiento en Buenos Aires: la Hacienda de la Chacarita, 1779-1784", en Cuadernos de Historia Regional, 15, Luján, pp. 67-96; " Labradores del instante', 'arrendatarios eventuales': el arriendo rural en Buenos Aires a fines de la época colonial", en M. BJERG y A. REGUERA, Problemas de la historia agraria. Nuevos debates y perspectivas de investigación, Tandil, IEHS, 1995, pp. 47-78; "'Según la costumbre del pays': 
Ante todo un problema de fuentes. Los arrendatarios aparecian poco mencionados en los padrones -salvo excepciones- y prácticamente no existían en las fuentes fiscales. A su vez, no eran demasiados numerosos en los protocolos notariales y cuando sí aparecían eran muy escasos, entre ellos los que hacian referencia a los tenedores de pequeñas parcelas. En los escasos libros de cuentas conocidos de las estancias su presencia era nula o muy poco significativa. Sin embargo, una incursión sistemática en las series Jesuitas y Temporalidades de Buenos Aires arrojó resultados completamente opuestos. ¿Se trataba, entonces, de un fenómeno, circunscripto a las tierras jesuitas? El trabajo sobre los fondos documentales judiciales y sucesorios demostró que no era asi. Allí su presencia parece remitir a otro mundo y los arrendatarios aparecen en pleitos por deslindes, mensuras, desalojos, deudas y -directamente- por cobro de arriendos.

Se podría pensar que esta opacidad documental reflejara la importancia de esta forma de tenencia de la tierra en la estructura agraria regional. Sin embargo, no eran estos problemas demasiado diferentes de los que habían afrontado los más importantes estudios en aquellas regiones americanas donde el fenómeno tiene confirmada centralidad, al punto que define el tipo básico de relaciones sociales en esos contextos: el valle central de Chile, el Bajío mexicano y los valles cochabambinos. Se trata de tres regiones muy diferentes entre sí y muy distintas cada una de ellas a Buenos Aires, pero en las cuales la investigación sobre el arrendamiento ha debido afrontar problemas comunes, muchos de los cuales se presentan también en el caso de Buenos Aires. Aún para el caso de los inquilinos chilenos, el ejemplo prototípico y clásico de campesinado supeditado colonial y convertido en imagen historiográfica de todo el campesinado chileno, estos problemas de fuentes no han podido ser eludidos. Como A. Bauer ha indicado "Como no recibian salario, como sus contratos solían ser verbales y como los problemas legales los solía resolver el hacendado fuera de los tribunales, los inquilinos eran los menos visibles de los habitantes del agro." La misma forma de los contratos ya sugiere varias pistas sobre su carácter y su misma reiteración en espacios tan distantes suscita varios problemas de explicación.

arriendo y costumbre en la campaña de Buenos Aires durante el siglo XVIII", en Boletín del Instituto de Historia Argentina y Americana Dr. Emilio Ravignani, 11, 1995, pp.39-64; y "Procesos de estructuración social en la campaña bonaerense (1740-1840)", mimeo, 1994. 
Nuestro interés por el enfoque comparado surge precisamente de algunos vacíos ineludibles que ofrece la documentación bonaerense y se atiene a una de las sugerencias claves de Marc Bloch: la posibilidad de recurrir a este método para completar vacíos documentales y para poder pensar el problema aunque más no sea todavía en términos de hipótesis que guien la investigación y la relectura de materiales a veces escasos y otras fragmentarios ${ }^{17}$. Pese a esta escasa visibilidad existe amplio consenso en señalar el valor de la costumbre en este tipo de relación así como se ha reconocido su amplia variación "de región a región, y aún de fundo a fundo" como han encontrado tanto Mario Góngora en Chile como David Brading en México. En Buenos Aires también era una relación regulada por la costumbre. Pero esta constatación implica todo un desafío: ¿no eran éstas las tierras "nuevas", las tierras "vacías" sobre las que habría de darse la expansión ganadera?

\section{Breve presentación de los casos de comparación.}

\section{La campaña de Buenos Aires.}

El arrendamiento se desarrolla en Buenos Aires junto a un conjunto más complejo y variado de formas de tenencia de la tierra que van desde la propiedad plena hasta la ocupación de hecho. Su relación con la agricultura es muy estrecha, aúnque aparezca también asociado a otros sectores productivos y tiene en ella dos modalidades predominantes: por un lado, en el área de chacras cercana a la ciudad; y por otro, en plena tierras de estancia -aún en zonas de frontera- y en especial entre las estancias.

El crecimiento de la producción agrícola porteña estuvo empujado por el crecimiento urbano pues el destino de esta producción era ante todo el mercado porteño salvo contadas excepciones- y probablemente con el tiempo los reducidos mercados que se iban conformando en los pueblos de campaña. Junto a ello, otra parte de la producción circulaba por fuera del mercado para el abastecimiento de los establecimientos agrarios y sobre todo para el sustento campesino. El mercado urbano que impulsaba su crecimiento era un mercado creciente y "cerrado" a la competencia externa pero las mismas

${ }^{17}$ M. BLOCH, Los reyes taumaturgos, México, FCE, 1988, p. 64. 
condiciones del mercado hacían de la agricultura una empresa muy peligrosa desde el punto de vista mercantil. ${ }^{18}$

La mayor parte de la producción cerealera era desarrollada en pequeñas explotaciones. Sin embargo, en el área de chacras aledaña a la ciudad, estas unidades coexistían con una serie de grandes chacras cerealeras que producían para este mercado. Las condiciones de la producción en esta zona han comenzado a salir de la penumbra. Hoy se sabe que cerca de la mitad de las unidades no disponían de la propiedad de la tierra y en similar proporción contaban con esclavos. ${ }^{19}$ No es mucho aún lo que se sabe de las grandes chacras ceraleras pero no hay duda que algunas (la de Diego Casero estudiada por Garavaglia o la Chacarita analizada por mí) eran realmente grandes, verdaderas haciendas. En tal sentido, no es extraño entonces que en esta zona los hacendados sean ante todo propietarios de chacras y generalmente además comerciantes y no criadores de ganado ${ }^{20}$. Estas grandes chacras combinaban la producción directa en base a trabajo esclavo y conchabado, con el arrendamiento de parcelas a campesinos que pagaban sus rentas generalmente en especie lo que les permitía asegurar la inserción de la empresa en el mercado, reduciendo costos de producción y abastecimiento y asegurando un ingreso mucho más estable y seguro que el de la propia producción. Es probable que la tendencia haya sido hacia la reducción del área de producción directa y al aumento del número de parcelas entregas en arriendo.

No es ésta la única tendencia que parece haberse operado. El área presenta la existencia de arrendatarios que parecieran prosperar en estas condiciones e incluso acrecentar su patrimonio de modo que no es raro encontrar arrendatarios con esclavos y

${ }^{18}$ Jorge GELMAN, "Una región y una chacra en la campaña rioplatense: las condiciones de la producción triguera a fines de la época colonial", en R. FRADKIN (comp.), La historia..., ob.cit., II, pp. 7-39.

19 Juan C. GARAVAgLIA, " Las chacras y quintas de Buenos Aires. Ejido y campaña, 1750-1815", en R. MANDRINI y A. REgUERA (comps.), Huellas en la tierra. Indios, agricultores y hacendados en la pampa bonaerense, Tandil, IEHS, 1993, pp. 121-146.

20 R. FRADKIN, " ¿Estancieros, hacendados o terratenientes? La formación de la clase terrateniente porteña y el uso de las categorías históricas y analíticas", en M. BONAUDO y A. PUCCIARELLI (comps), La problemática agraria. Nuevas aproximaciones, Buenos Aires, CEAL, 1, 1993, pp. 17-58. 
peones además de comerciantes de menor cuantía que toman tierras en arriendo. Un aspecto más no puede ser pasado por alto. La evidencia disponible indica que el arrendamiento en estas condiciones es pagado sobre todo en especie y, probablemente, en proporción a la cosecha. Ello no es, por cierto, independiente del sistema de crédito y comercialización vigente que conformaba una esfera de la circulación muy concentrada y especulativa. $^{21}$

Pero el arrendamiento se difunde también lejos de la ciudad. Aqui aparece una de las modalidades básicas de su difusión. No considero en este momento las formas de arriendo y aparcería vinculadas directamente con la cría de ganados sino sólo esta presencia del arrendamiento agrícola en la tierra de estancia. Las fuentes más conocidas dieron cuenta de estos arrendatarios: son "la polilla de la campaña". El cultivo de cereales se desarrolló tanto al "interior" como al "exterior" de las estancias y alrededor de los pueblos y fortines de campaña. ${ }^{22}$ Es aquí donde el arriendo aparece más directamente vinculado al suministro de mano de obra y a la afirmación del derecho de propiedad antes que a la extracción misma de la renta. En su mayor parte, estos arrendatarios son campesinos que operan en muy reducida escala, abonan sus rentas en especie al tanto de lo sembrado y manifiestan una extrema movilidad espacial e inestabilidad en la relación de arriendo. Es en estas condiciones que el arriendo aparece sólo como una de las formas de acceso a la tierra junto a otras muy difundidas como la agregación.

\section{El valle central de Chile.}

El valle central de Chile tiene una importancia relevante pues allí aparece la figura del inquilino. El libro de M. Góngora testimonia con claridad la visión de los arrendatarios como campesinos sometidos a un régimen semejante al colonato ${ }^{23}$, y fue convertido por la

21 J.C. GARAVAGLIA, "El pan de cada día: el mercado del trigo en Buenos Aires, 1700-1820", en Boletín del Instituto de Historia Argentina y Americana Dr. Emilio Ravignani, 4, 1991, pp. 7-30.

22 J.C. GARAVAGLIA, "La agricultura del trigo en las estancias de la campaña bonaerense: tecnología y empresas productivas, 1750-1815", en R. MANDRINI y A. REGUERA (comps.), Huellas..., ob. cit., pp. 91-120.

${ }^{23}$ Mario GóNGoRA, Origen de los "inquilinos" de Chile central, Santiago de Chile, Editorial Universitaria, 1960. 
historiografía casi como un modelo interpretativo cuando se aborda el tema del arrendamiento. ${ }^{24}$ Para Góngora el inquilinaje fue precedido en el siglo XVII por el préstamo de tierras, esta modalidad se desarrolla en una época en la cual las tierras son poco explotadas y como modo de atraer pobladores teniendo como función primordial la de atestiguar los derechos del propietario a la tierra, custodiar los límites y los ganados. Lo interesante es que esta modalidad suele ser denominada "arriendo" aunque muchas veces no suponga el pago de rentas y constituye una forma jurídica singularmente flexible que supone cierta gratuidad y precariedad. Esta modalidad aparece ligada al escaso valor del suelo, al poblamiento disperso y es previo, por lo tanto, a la valorización de los cultivos: es, de este modo, previo al crecimiento de la población y del comercio que provocarán que las tenencias se multipliquen y la dependencia personal del tenedor sea el vínculo predominante.

A lo largo del siglo XVIII la denominación que tiende a generalizarse es la de arrendatarios. Se trata de una forma de tenencia precaria en la cual es rarísimo que se pacten plazos. Ella se extiende mucho en el área de chacras aledaña a Santiago y en particular en las destinadas a viñas donde suelen alquilarse como peones temporales del dueño de la tierra. Durante la primer mitad del siglo es posible ver que entre ellos existen hombres de variada condición y reconocimiento social y predominan los mestizos que incluyen buena parte de la población de origen indígena ahora formalmente libre de toda sujeción territorial. El arrendamiento se adapta mejor a las nuevas condiciones pues supone convenios libremente pactados y el poblador no está sujeto a trabajo permanente, sino a ciertas faenas convenidas y al pago de un canon.

Pero hacia fines del siglo XVIII la situación se ha modificado. Ahora la denominación más frecuente es la de inquilino aunque todavía no elimina a la de arrendatario y suele combinarse con ésta: el inquilinaje se implanta ante todo entre trabajadores inmigrantes a la hacienda y los arrendatarios deben afrontar crecientes obligaciones laborales. La obligación más universal pareciera ser la de asistencia a los rodeos que con el tiempo incluye la de aportar peones. Se produce así un ensanchamiento de las obligaciones laborales que trasluce la tendencia a hacer más costosa la tenencia. De este modo, coexisten tres formas de dependencia: la esclavitud, el peonaje y el

24 Magnus MORNER, El colonato en la América meridional, Estocolmo, Instituto Iberoamericano de Estocolmo, 1970. 
arrendamiento hasta que a lo largo del siglo XIX se conformen dos sectores laborales diferenciados: los peones y los inquilinos.

El proceso formativo del inquilinaje aparece directamente vinculado a la valorización de la tierra y de los cultivos. M. Carmagnani analizó el impacto de la exportación triguera al Perú entre 1660 y 1830. Durante un primer ciclo, los precios del trigo son altos y las tierras abundantes y ello volcó a los propietarios a fomentar el establecimiento de arrendatarios como fuente de ingreso y modo de acumular trigo. En el segundo ciclo -durante la segunda mitad del XVIII-, los precios bajan y la producción se sostiene convirtiendo a los arrendatarios en especie en arrendatarios de servicio, en inquilinos que suministran trabajo gratuito a cambio de la tenencia. ${ }^{25}$ De acuerdo a ello, el arrendamiento puede ser visto como un mecanismo de acceso a fuerza de trabajo escasa mediante el cual la hacienda reduce sus costos de producción y afronta la baja de sus precios de sus productos de exportación. C. Kay ${ }^{26}$, por su parte, ha interpretado esta transformación señalando que mientras no se desarrolló un mercado de exportación predominó un sistema de hacienda del tipo Grundherrschaft (es decir uno en el cual el terrateniente no desarrolla la producción sino que divide la hacienda entre aparceros campesinos que le pagan una renta en especie o dinero) ; luego, con el crecimiento del mercado de exportación las haciendas aumentaron las tierras bajo cultivo directo en el mismo sentido que un sistema Gutsherrschaft de Europa oriental. En ambos casos, la economía campesina sostiene la acumulación pues es la que suministra o mano de obra o los productos de renta que se comercializan. La naturaleza de la relación se ve con claridad en el hecho de que la cantidad de tierra en usufructo se calculaba en base a la cantidad de obligaciones laborales pero también en que los inquilinos obtenían derechos de acceso a pastos, leña y otros recursos, además de las parcelas de trabajo propio. De este modo, dentro del inquilinaje se desarrollaban toda una gama de posiciones. Como ha indicado Bauer ${ }^{27}$ la clave parece estar en la solidez de la propiedad territcrial chilena y su

\footnotetext{
${ }^{25}$ M. CARMAGNANI, Les Mecanismes de la Vie Economique dans une Societé Coloniale. Le Chilé 1680-1830, Paris, 1973.

${ }^{26}$ C. KAY, El sistema señorial europeo y la hacienda latinoamericana, México, Era, 1980.

${ }^{27}$ A. BAUER, "La Hacienda 'El Huique' en la estructura agraria del Chile decimonónico", en E. Florescano (comp.): Haciendas, latifundios y plantaciones en América Latina, México, Siglo XXI, 1975, pp. 393-413.
} 
grado de control efectivo sobre el $80 \%$ de la tierra de cultivo. En estas condiciones la práctica más frecuente era dar tierra a cambio de trabajo.

Pero aún este caso -clásico y paradigmático- vino a ser revisado. Para Salazar ${ }^{28} \mathrm{el}$ nudo del problema consiste en centrarse en la economía campesina evitando subsumir al conjunto de la vida campesina a partir de los rasgos de algunos de sus componentes (como los inquilinos) y superar los enfoques centrados exclusivamente en el interior del mundo de la hacienda. Esta perspectiva le permite ofrecer una visión "ensanchada" del campesinado. A lo largo del largo período 1650/1850 Salazar reconoce un proceso básico de campesinización resultado de la necesidad de las haciendas de obtener fuerza de trabajo segura y de las masas vagabundas de arrancharse, siendo el inquilinaje sólo uno de los ramales de ese proceso que no puede reducirse a él. En esas condiciones, no sólo no fue tan multitudinario como se pensaba sino que tampoco fue irresistible para los campesinos que prefirieron formas de acceso no peonal a la tierra. El componente primordial de la campesinización fue la masa de vagabundos arrendatarios dotados de alta movilidad espacial y que desarrollaron una economía pequeño empresarial. Desde esta perspectiva, Salazar propone una interpretación diferente de los efectos del ciclo expansivo de la exportación de cereal.

Ante todo, los latifundios fueron incapaces de satisfacer el conjunto de la demanda externa. Frente a ello impulsaron el inquilinaje hacia el interior de la hacienda y la comercialización de los excedentes del campesinado independiente, por otra. Cuando a partir de la tercera década del siglo XIX comenzaron a importar maquinaria agrícola ello forzó a los inquilinos a convertirse en peones obligados. Desde su perspectiva, entonces, el cambio básico que introdujo la exportación de cereal fue romper con los arrendamientos laxos asociados a los préstamos de tierras y volcar a los campesinos al arriendo de carácter mercantil para participar del ciclo expansivo; fue ello lo que expandió enormemente el número de arrendatarios e inquilinos a través de los convenios de compañía. Pero tal asociación comenzó a romperse hacia 1760 por el alza de los precios de la tierra, los menores precios del cereal para los productores y el aumento de los

${ }^{28}$ G. SALAZAR, Labradores, peones y proletarios. Formación y crisis de la sociedad popular chilena del Siglo XIX, Santiago de Chile, Ediciones Sur, 1989. 
arriendos y los intereses y la carga impositiva. En estas condiciones, la presión se convirtió en pago con trabajo obligatorio convirtiendo al comercializador en patrón. De este modo, ello forź́ un fuerte aumento de la dependencia peonal y el quiebre de la posible empresa campesina. El inquilinaje es así para Salazar la historia de un campesinado frustrado.

El caso chileno permite ver que el fenómeno del arrendamiento, más que definir un tipo de productor, es una relación cuyos significados e implicancias dependen de su contexto, que su difusión estuvo asociada a fenómenos de movilidad de la población rural de blancos pobres y de mestizos y que sus características dependieron de los ciclos del mercado, de la disponibilidad de tierra y de la solidez del régimen de propiedad. Pero también que, aún en condiciones de alta concentración de la propiedad y de la comercialización, el arriendo ha sido compatible con formas de producción diversa que van desde la peonización campesina hasta la formación de una masa de pequeños productores mercantiles.

\section{El Bajío mexicano 29.}

Los estudios monográficos regionales han tenido en México resultados notables. Uno de ellos -y no de menor importancia- es haber minado muchas de las creencias previas sin poder proporcionar una teoría general explicativa. De este modo, por ejemplo, Bazant puso en evidencia que en el área de San Luis de Potosí la masa rural no estaba compuesta exclusivamente por peones acasillados; por el contrario lo que encontró fue sobre todo un conglomerado numeroso de arrendatarios y aparceros endeudados. ${ }^{30}$ Pero la masa de arrendatarios no es tampoco homogénea tanto que Bazant sostiene que "ser arrendatario no dice nada sobre la posición social ni sobre el papel de la persona en la economía de la haciendd". Menos claros aún son sus orígenes: la hipótesis de Bazant es que se trata de ocupantes de hecho de tierras no utilizadas que la hacienda prefirió

${ }^{29}$ Para este caso nos basaremos en D. BRAIDING, Haciendas y ranchos en el Bajío. León 1700-1860, México, Grijalbo, 1988.

30 J. BAZANT, Cinco haciendas mexicanas: tres siglos de vida rural en San Luis de Potosi 1600-1910, México, 1975 y "Peones, arrendatarios y aparceros en México, 1851-1853", en E. FLORESCANO, Haciendas..., ob.cit., pp. 306-326. 
legalizar convirtiéndolos en arrendatarios por una renta fija por cada solar y otra variable de acuerdo a la cantidad de sus sembrados y pastoreo. De este modo, encuentra varios tipos de arrendatarios: de tierras y pasturas, sin pastura y sólo para establecer su casa. A ellos se agrega un grupo poco numeroso de medieros, en su origen, arrendatarios muy pobres que recibían a préstamo las semillas, los aperos y los bueyes.

La presencia de arrendatarios aparece acentuada en aquellas tierras donde la hacienda mantenía un vago control del territorio. De este modo, en las tierras altas de Jalisco o Michoacán se ha podido ver la instalación de arrendatarios que, luego de la crisis de independencia, lograron convertirse en propietarios de la tierra. ${ }^{31}$ Desde la perspectiva de Brading en México - como en Guatemala - puede reconocerse una tendencia en la difusión del arrendamiento: en fases de contracción de la demanda los terratenientes abren sus tierras a arrendatarios y arrimados. En las zonas periféricas del norte lo hacian a cambio de una renta nominal y a veces con alguna obligación laboral remunerada y aún cuando se fijaran las rentas en términos monetarios, se pagaban al menos en parte con mano de obra. Ello permitía a la hacienda reducir su dependencia de los peones acasillados. Pero esta expansión del arrendamiento significó una amenaza para la hacienda media cuando la economía entraba en una fase de auge de la demanda: entonces ese tipo de haciendas se encontraba con una economía campesina competitiva en el mercado de granos. En esas condiciones de precios inevitablemente bajos, la función de los arriendos era suministrar un ingreso efectivo hasta que las crisis periódicas traían la recompensa y eliminaban competidores. Ello abrió a los terratenientes la posibilidad de convertirse en meros rentistas, tanto a aquellos ubicados muy cerca del mercado como a los que por estar tan alejados no les quedaba otra alternativa al abandono. En el siglo XIX, apoyándose en el crecimiento de la población y de los precios de la tierra tendió a generalizarse el régimen de aparcería.

Pero ¿qué sucedió específicamente en el Bajío? Se trataba de un área de frontera de reciente colonización, básicamente mestiza que en el siglo XVIII se convirtió en un área central muy urbanizada. Sus haciendas se parecen a las de San Luis de Potosí en cuanto a su estructura tripartita de mano de obra (peones residentes, arrendatarios y aparceros y peones temporarios) y son el resultado de una compleja secuencia de colonización interna. Su presencia era resultado de un lento cambio operado a lo largo del siglo XVIII.

${ }^{31}$ L. González, Pueblo en vilo, México, 1968. 
Por un lado, hacia 1700, era muy extendida la existencia de ranchos de pequeños propietarios. Por otro, al principio los arrimados fueron bienvenidos como medio de asegurar la posesión de la tierra pero luego se les incrementaron las rentas hasta convertirlas en una importante fuente de ingresos para la hacienda. Su expansión a lo largo del siglo, en especial en las décadas de 1740 a 1770, significó un proceso de amalgama de propiedades realizado por el capital mercantil y la conversión de muchos pequeños propietarios en arrendatarios $y$ medieros. Pero la masa de rancheros arrendatarios no era aquí tampoco uniforme pues incluía desde rancheros emprendedores que contrataban mano de obra hasta campesinos en el límite de la subsistencia. Sin embargo, una parte de ellos -generalmente criollos- pudo resistir el embate de la hacienda y beneficiarse con el auge de la demanda posterior a 1770. Su prosperidad fue socavada no tanto por la pérdida de las tierras sino por la transformación del sistema de arriendo del pago en efectivo al régimen de aparcería.

De esta manera, el Bajío ofrece un sugerente marco de referencia. Pone de manifiesto el proceso de constitución y la capacidad de persistencia de un régimen de pequeña producción rural -y aún de propiedad- compatible con un proceso general de expansión de la gran hacienda y que se convierte en un problema central cuando la fase de auge de la producción cerealera iba a mostrar la existencia de una economía campesina competitiva en el mercado. Esta economía campesina no es necesariamente, por tanto, de autoconsumo y tampoco resultado del sustrato indígena: surge de una masa de población móvil esencialmente mestiza en un área de colonización. Aquí, la producción cerealera está orientada esencialmente al mercado urbano regional y su expansión se asienta en el crecimiento de ese mercado.

\section{Los valles de Cochabamba.}

La región de Cochabamba, ha señalado Larson ${ }^{32}$, es un claro ejemplo de un área donde las relaciones serviles de trabajo en las haciendas fueron reforzadas por los imperativos de la economía minera. Se trata de una región muy diferente de otras de altura por su complejo sistema de tenencia de la tierra y la abundante población mestiza pues se había convertido en un polo de atracción de migrantes. Además, a diferencia de

\footnotetext{
32 B. LARSON, Explotación agraria y resistencia campesina. Cinco ensayos históricos sobre Cochabamba (siglos XVI-XIX), Cochabamba, CERES, 1983.
} 
otras provincias cercanas como Chayanta, la parte indígena de la población se componía principalmente de forasteros sin tierra y la mayor parte de los que vivían en tierras de hacienda eran arrenderos que tenían derechos de usufructo y de movilidad geográfica.

Desde fines del siglo XVI Cochabamba se convirtió en el gran área cerealera de abastecimiento de Potosí y hacia el siglo XVIII la mayor parte de la producción estaba en manos de pequeños arrendatarios y aparceros. Las tierras de hacienda fueron fragmentadas y alquiladas a arrendatarios que pagaban sus rentas en dinero o especie y muchas veces debían prestar servicios laborales por el usufructo. Sin embargo, al menos teóricamente, este tiempo de trabajo estaba regulado por el Estado según el avalúo de la tierra arrendada y no fijado de modo arbitrario. La situación de todos los arrendatarios no era la misma y muchos de ellos reclutaron jornaleros. De este modo, la fuerza de trabajo rural se estaba estratificando en arrendatarios, subarrendatarios y jornaleros.

Larson encuentra dos procesos encadenados a la crisis del Estado colonial: por un lado, la contracción del mercado potosino y por lo tanto de las exportaciones cochabambinas; por otro, el crecimiento del número de pobladores sin tierras. El crecimiento de la economía campesina permitió a la clase terrateniente convertirse en una clase de rentistas $y$, a fines del siglo XVIII, una parte de ella pudo invertir en la usura, especialmente de diezmos, y mediante ello acaparar el mercado del cereal de exportación. En esas condiciones lograron impedir que la economía campesina derivara en un campesinado propietario. La tenencia precaria en arriendo era la forma predominante de control sobre la fuerza de trabajo. Los arrenderos debían pagar con obligaciones laborales, realizar servicios domésticos (pongueaje), suministrar sus propios animales y trabajadores adicionales. Junto a esta modalidad de arrendamiento coactivo se extendieron los contratos de compañía. Los propietarios suministraban los factores básicos y los arrendatarios su trabajo recibiendo a cambio entre el 20 y el $50 \%$ de la cosecha y ciertos derechos de usufructo. La hacienda combinaba estas formas de trabajo junto a la existencia de jornaleros y en el curso del tiempo los campesinos se movían por estas variadas formas de trabajo. Junto a ello era de práctica que el hacendado exigiera el trabajo de mujeres e hijos del arrendero quien, además, solía tener que movilizar a su parentela y contratar jornaleros a su costo que terminaban como subarrendatarios o arrimantes del arrendatario. 
De este modo, a fines del XVIII la coacción había permitido conformar un campesinado sin tierras, intrincadamente estratificado. La difusión del arrendamiento contrajo la producción directa de la hacienda y obturó la formación de un "campesinado propietario con racionalidad mercantil".

\section{El arrendamiento bonaerense en perspectiva comparada.}

Es posible realizar un ejercicio comparativo de estos casos a partir de dos grandes perspectivas: por un lado, a partir de las prácticas y las normas efectivamente observables en cada caso. Por otro, en un nivel más analítico, a partir de las interpretaciones y comparaciones propuestas por los estudiosos más relevantes. Comencemos por este segundo modo.

\section{a) Examen de las comparaciones disponibles.}

El caso del valle central de Chile permite extraer algunas conclusiones preliminares si se lo compara.con Buenos Aires. En principio, la situación tiene en las fases iniciales bastantes similitudes y, en ambas regiones, se encuentra un proceso de difusión del arrendamiento asociado a la disponibilidad de tierras y a la escasez de brazos en un marco de población rural móvil, ante todo mestiza, criolla y hasta de españoles pobres. En esas condiciones, los arrendamientos laxos parecieran ser una forma de atracción orientada a constituir un reservorio de mano de obra de asalariados temporarios y en las ganaderas de afirmación del derecho de propiedad y aseguramiento de los límites de las propiedades en formación.

Que la situación podía ser comparable no pasó inadvertido. Halperín observó que los estudios recientes sobre el área bonaerense "esbozan e/ retrato de una sociedad rural no muy diferente de la del Valle Central de Chile". Pero para Halperín "Las condiciones que habian hecho posible esta coexistencia no sobrevivieron al fin del régimen colonial [...y...] un cambio radical en el mapa económico del Litoral y de las Pampas, que vino a aflojar el lazo originario entre ganadería y pequeña agricultura" ${ }^{33}$. La visión de Halperín tiende a

33 T. HALPERÍN DONGHI, "Clase terrateniente y poder político en Buenos Aires (1820-1930)", en Cuadernos de Historia Regional, 15, Luján, 1992, pp.14-15. 
señalar que la diferencia crucial que habría entre ambas áreas regionales hay que buscarla en el siglo XIX, observando una evolución sustancialmente diferente desde una fase muy semejante en el siglo anterior. Esta es una visión muy apegada a una de todas las posibilidades que expresaba la existencia del régimen de arriendo, la de suministro de mano de obra a través de un régimen de colonato pero ella da cuenta más de la figura del agregado que de la del arrendatario. ${ }^{34}$ No es, por cierto, que ello no haya sido así, sino que es una perspectiva restringida del problema.

Arrendatarios y agregados muchas veces se traslapan ante nuestros ojos pero las fuentes suelen ser reiterativas en discriminarlos. Ambas eran formas bastante informales e inestables de relación y de tenencia y ambas se regían generalmente por el imperio de la costumbre; pero, hasta donde se sabe, mientras el agregado debía siempre algún tipo de obligación laboral no remunerada no era ésta la situación de quienes aparecían catalogados como arrendatarios. Pero fundamentalmente no es posible aún dar debida cuenta del problema hasta que se disponga de estudios más firmes sobre esta elusiva figura de la pampa bonaerense. Los indicios actualmente disponibles sugieren una fuerte presencia de esta figura social, "un personaje típico de la frontera argentina desde los tiempos coloniales hasta el siglo XX $X^{\prime \prime} .{ }^{35}$ Es posible que en ese largo trayecto la figura del agregado se haya transformado: al parecer en el siglo XVIII excluía decididamente la remuneración salarial y a fines del XIX, ésta era parte inescindible de su presencia. De ser así -y por ahora no hay posibilidades de resolverlo fehacientemente- la agregación no habría sido obstáculo para la difusión de formas de trabajo asalariado. Que se haya expandido durante el siglo XIX no es extraño dada la importancia de la esclavitud en la disponibilidad de fuerza de trabajo permanente de la estancia porteña hasta por lo menos la década de 1830.

¿Qué puede aportar al respecto la perspectiva comparada? Como ya se dijo, la inquilinización fue parte de un proceso más amplio de campesinización frustrado. De modo análogo -pero en condiciones y con características muy diferentes- tanto en el Bajío como en Cochabamba se obturaron también las posibilidades de un desarrollo campesino independiente.

${ }^{34}$ Cf. una perspectiva semejante en Carlos MAYO, Estancia y sociedad en la pampa. 17401820, Buenos Aires, Biblos, 1995, cap.IV.

35 Eduardo MIguez, " La frontera de Buenos Aires en el siglo XIX. Población y mercado de trabajo", EN R.MANDRINI Y A. REGUERA (comps.), Huellas..., ob.cit., p. 203. 
Lo que las actuales investigaciones sobre Buenos Aires sugieren es, ante todo, la imposibilidad histórica de operar un proceso efectivo y firme de inquilinización. Y ello no puede ser atribuido exclusivamente al carácter ganadero de la clase terrateniente que está en formación. Porque entre las sustanciales diferencias que presenta Buenos Aires frente a los otros casos considerados cabe señalar que la estructura agraria contaba con disponibilidad de tierra fértil que aún no estaba efectivamente apropiada o que no era utilizada. En los otros tres casos la difusión del arrendamiento aparece vinculada más con estrategias de los propietarios que atraen o permiten la presencia de diversos tipos de pobladores en sus tierras que lo que pareciera haber sido el rasgo distintivo de su difusión en las tierras de estancia bonaerenses: su instalación suele preceder a la afirmación efectiva de los derechos de propiedad, especialmente en la frontera. Las otras regiones consideradas no son, a fines del siglo XVIII, un área fronteriza y no es casual que las modalidades del arrendamiento pampeano sean muy semejantes a las de las zonas alejadas del valle central de Chile o a las del Bajío cuando eran zonas en proceso de colonización.

En las otras regiones el proceso de apropiación de la tierra ya está consolidado y estabilizado. En Buenos Aires, en cambio, la situación era muy diferente y aún en la zona de más antigua colonización la superposición de títulos era muy frecuente y existieron por mucho tiempo espacios disponibles para poner en producción. Según hemos podido constatar los arrendatarios de fines del siglo XVIII vivían en los intersticios que ofrecía tanto la estructura agraria como los sistemas normativos que ella disponía y sus perspectivas posteriores dependieron de la persistencia de esos espacios intersticiales. Ahora bien, esos espacios no eran sólo territoriales sino también mercantiles. Si en Buenos Aires no parece haberse operado una generalizada y completa peonización de la población rural tampoco era -justamente- el caso paradigmático de formación de un campesinado parcelario independiente. Por el contrario, más bien pareciera haberse dado la persistencia y transformación de un conglomerado de pequeños productores e inclusive de propietarios de tierras y de ganados plenamente incorporados al mercado. Si como parece la magnitud del sector de productores cerealeros se mantuvo relativamente estable, lo que sí se incrementó sustancialmente fue el segmento de criadores que, como aquellos, tenían una orientación central hacia el mercado local de consumo, en este caso de carne. Los arrendamientos laxos y la aparcería no desaparecieron con el ciclo expansivo de las exportaciones y se adaptaron bien a las nuevas condiciones. 
Son estos espacios intersticiales los que se fueron cerrando y desapareciendo en las otras regiones consideradas de un modo mucho más acusado. De este modo, fenómenos en primera impresión análogos expresan realidades muy diferentes y no es la existencia misma del fenómeno sino el contexto en el que se inscriben el que les da su significado. En Buenos Aires es posible que sea la figura del agregado la que responda a esta lógica de atracción de mano de obra escasa y quizás también la difusión de la aparcería ganadera, pero ese no parece ser el rasgo definitorio del conjunto del fenómeno del arrendamiento, al menos cuando está vinculado a la producción de trigo.

El mejor intento de inscribir su objeto de estudio en una perspectiva comparada es el realizado por B. Larson. En Cochabamba el arrendamiento no era - como en Chile o en el Bajío - un modo de controlar mano de obra escasa sino un mecanismo implementado por los terratenientes para disminuir costos de producción mediante la administración señorial que los hiciera menos vulnerables a los ciclos del mercado. Era así una respuesta a un mercado estrecho en condiciones de creciente presión poblacional sobre la tierra. De este modo, se presenta una situación que es en cierto sentido semejante al arrendamiento de tierras agrícolas cercanas a Buenos Aires. Para Larson "En Hispanoamérica no puede hablarse de un conjunto prescrito de circunstancias históricas que dieron lugar al arrendamiento como el modo de producción predominante". Esta observación es decisiva pues sitúa al fenómeno social analizado en un contexto histórico preciso, alejado de cualquier explicación genérica. Sin embargo, ofrece una visión de Chile y el Bajío demasiado semejante: "en ambos casos, el creciente predominio del arrendamiento se debió principalmente a la necesidad de obtener un volumen estable de fuerza de trabajo en un periodo de crecientes exportaciones de grano. "En Cochabamba, en cambio, "Estas formas de control de la fuerza de trabajo cristalizaron durante un prolongado período de exportaciones limitadas o decrecientes de grano, por un lado, y en una situación de creciente presión demográfica sobre la tierra, por otro.[...]La función primordial del sistema de arrendamiento no era entonces la de movilizar mano de obra escasa para la agricultura en las tierras de hacienda, como fue el caso del Bajío mexicano o del valle central de Chile. Era más bien un medio de parcelar la tierra en manos de pequeños productores con objeto de reducir los costos de producción desvinculando la producción de la administración directa del hacendado".

La perspectiva comparativa de Larson le permite reconocer, entonces, que una misma forma de tenencia - el arrendamiento- no tiene la misma explicación causal y ni se 
corresponde a un contexto de circunstancias específicas sino que, por el contrario, la misma forma puede ser originada en contextos muy diversos: el arriendo aparece como una solución apta en contextos diametralmente diferentes en cuanto a disponibilidad de mano de obra, tanto donde ésta es muy escasa como donde sobreabunda. Su incidencia no es la de una causa sino que está centrada en las condiciones que habrán de afrontar estos arrendatarios.

El cotejo de Cochabamba con Buenos Aires sugiere que esta modalidad encontrada por Larson es también compatible con una producción cerealera que no decaiga sino que crezca con ritmo sostenido y el hecho de que no sea una producción exportable sino orientada al mercado local de consumo puede haber incidido en brindar mayores posibilidades a los arrendatarios. Esta atracción del mercado para los comportamientos campesinos tiene una importancia capital: en una región en la cual a pocos kilómetros era posible hallar tierras disponibles por bajos montos de arriendo y aún sin canon, hemos encontrado que una parte de los arrendatarios se arraigan a la tierra aún cuando las rentas sean mayores y se incrementen. La localización debe haber tenido al respecto una importancia decisiva. En los alrededores de Buenos Aires, el ejido y aún dentro de la misma traza urbana es posible registrar la presencia de todo un conglomerado de pequeños productores, buena parte de ellos arrendatarios de tierras de quinta instalados en antiguas grandes chacras parceladas, en "sitios" y en las zonas bajas e inundables. Se parece haber conformado así un mundo campesino al interior de la vida urbana en un proceso bastante semejante al que Salazar describe para Santiago. ${ }^{36}$

Si la reducida campaña bonaerense presenta las complejidades señaladas, ello permite advertir que no es demasiado conveniente la asimilación de las condiciones de Chile y el Bajío que realiza Larson. Esta posibilidad ya había sido intentada por Góngora. Utilizando la información aportada por Chevalier advirtió una fuerte semejanza con Nueva Galicia. Allí también la hacienda arrienda a rancheros en sus límites en los que crian pocos ganados y realizan un pequeño cultivo: se trata de algo semejante al préstamo de tierras que, como en Chile - o en Buenos Aires-, es efectuado no a indios sino a españoles pobres y hombres sueltos. Pero, a diferencia de Chile, no parecen estar sometidos a obligaciones laborales, ni siquiera a la asistencia de rodeos, una cuestión clave para seguir la marcha del arrendamiento al inquilinaje. Para Góngora el elemento más semejante al inquilino se

\footnotetext{
${ }^{36}$ Cf. nuestro trabajo "Las quintas y el arrendamiento en Buenos Aires, siglos XVIII y XIX", mimeo,
} 1996. 
encuentra entre los arrendatarios de Nueva Granada, generalmente españoles pobres recién llegados y mestizos. Allí también el arrendatario esta obligado a asistir en los rodeos. Nuestra evidencia al respecto es, todavia, muy escueta. Las fuentes dan escasa cuenta de "obligaciones laborales" de los arrendatarios y sólo las hemos podido constatar en la Chacarita aunque no podamos descartarla en otras situaciones. Pero lo que sí muestra es la fuerte presencia de población migrante de orígenes muy diversos entre los arrendatarios, una regularidad muy fuerte en todas las regiones consideradas; en términos culturales el mundo del arrendamiento es un mundo mestizo cualquiera sea la forma de catalogación de los padrones de la época.

El interés que suministra el caso chileno es que muestra la transformación de la relación de arrendamiento de una forma laxa a otra compulsiva no por una caída de la demanda y las exportaciones sino de los precios. Es decir que, en consecuencia, el inquilinaje se convierte en un mecanismo de reducción de costos para la hacienda, lo que acerca más esta situación a la que describe Larson en Cochabamba que Brading para el Bajío. En Buenos Aires, hasta donde se sabe, esta no parece haber sido la situación: si durante el siglo XVIII la producción agrícola acicateada por el crecimiento de la demanda fue en aumento, los precios del trigo -aunque muy oscilantes- tuvieron una tendencia al alza, en especial en las primeras décadas del siglo XIX hasta que la apertura a las importaciones de harina los detengan. ${ }^{37}$ Los precios del vacuno, en cambio, tuvieron una tendencia general negativa hasta mediados de la década de 1810 , a partir de cuando tienen un fenomenal repunte junto al conjunto de los precios agrarios. Pero, ¿qué pasa con el precio de la tierra? Como ha indicado Garavaglia "es notable la estabilidad -dentro de una tendencia general bastante deprimida- que hay hasta fines del periodo y también es llamativa la tardía reacción de los precios de la tierra" que se levantan mucho después, en la década de 1820. Ello es congruente con la información que disponemos sobre la difusión del arrendamiento en el período: muestra la "sensibilidad" de estos arrendatarios

\footnotetext{
${ }^{37}$ R. ROMANO, "De nuevo acerca del movimiento de los precios en Buenos Aires del siglo XVIII", en Boletín del Instituto de Historia Argentina y Americana Dr. Emilio Ravignani, 6, Buenos Aires, 1992, pp. 149-162; L. JOHNSON, "Salarios, precios y costo de vida en el Buenos Aires colonial tardio", en idem, 2, 1990, pp. 133-158 y "Perspectivas encontradas: Romano, Johnson y la historia de los precios en el Buenos Aires colonial", en idem, 6, 1992, pp. 163-172; J.C. GARAVAGLIA, "Precios de los productos rurales y precios de la tierra en la campaña de Buenos Aires: 1750-1826", en Boletín del Instituto de Historia Argentina y Americana Dr. Emilio Ravignani, 11, BS.As, 1995, pp. 65-112.
} 
a los movimientos del precio del mercado y sustenta la hipótesis de su difusión y del carácter mercantil de estos productores. Si además se considera el retraso con que el precio de la tierra acompaña estos movimientos ello debe haber incidido notoriamente en los montos de las rentas.

Tenemos así una situación para la mayor parte del período de precios de la tierra bajos y estables y montos de arriendo del mismo tipo pero en condiciones de importante variación por zonas. Nuestra información cualitativa sugiere que los montos de arriendo son muy diferentes por zona y tipo de cultivo de modo que se duplican en las cercanías de la ciudad frente a las zonas de frontera -donde pueden llegar a ser nominales sino nulos- $y$ también lo hacen en cuanto al tipo de cultivo (el trigo frente al maíz); y ello, es congruente con la variación espacial que Garavaglia ha demostrado de los precios de la tierra.

Todo ello pone de relieve los rasgos más específicos del fenómeno del arrendamiento en Buenos Aires en una perspectiva comparada y sugiere que si hubo algo semejante a un proceso de inquilinización de estos arrendatarios sólo pudo haberse producido (insisto: si es que se produjo) después de la década de 1820. Pero aquí cabe señalar otra especificidad de la región bonaerense: la región se adapta mucho más rápido y mejor a las nuevas condiciones abiertas por la independencia, al menos mucho mejor que el Bajío o Cochabamba. La difusión de la aparcería ganadera en un contexto de expansión de las tierras disponibles y de precios bajos señala un camino que no parece apuntar -por cierto- al inquilinaje.

En todo caso, si ni aún en Chile conveniente subsumir a los arrendatarios en el inquilinaje, menos lo sería en un contexto como el bonaerense. $Y$ al respecto hay una fuerte convergencia en estos estudios. La propia información de Góngora permite reconocer que las dos figuras sociales no son asimilables ni en términos cronológicos ni sociales: mientras los inquilinos parecen estar siempre asentados a distancia de las casas de la hacienda, cerca sólo aparecen arrendatarios y en las tierras de acequia y en la misma hacienda pareciera haber un pequeño grupo de arrendatarios medios y una masa de inquilinos pobres. Esta constatación nos parece muy significativa y remite a las posibilidades abiertas en la estructura agraria y a los intersticios que ella puede presentar. El estudio de Brading puso de relieve la existencia de una complejidad insospechada en el 
patrón de tenencia de la tierra y de una masa de pequeños propietarios y arrendatarios, los rancheros, cuya importancia no reside tanto en su número como en el lugar estratégico que ocupaban, entre la élite terrateniente y la masa rural. A una conclusión semejante arribó Van Young para Guadalajara. ${ }^{38}$ Aún en el caso de alto grado de coacción como el de los inquilinos aparecen figuras como las del "peón obligado" conchabado por el propio inquilino y a veces también arrimados y agregados a su rancho. Del mismo modo, el subarriendo y el jornalero acompañan la figura del arrendatario cochabambino.

La evidencia de Buenos Aires, no es -al respecto- tampoco original: aquí también en torno a una misma relación jurídica con la tierra se han desarrollado una variedad de relaciones sociales de producción donde la coacción se orienta a convertir a pobladores sin canon en arrendatarios o, en su defecto, a forzar su traslado hacia tierras mucho más alejadas y convertirlos de este modo en un medio para asegurar la frontera. Lo que parece claro, sin embargo, es que la coacción no llega a ser el elemento que define la relación. Este mundo rural subalterno seguirá siendo escasamente controlable y extremadamente móvil. La combinación de, por un lado, posibilidades de movilidad espacial y, por otro, el alto grado de mercantilización e inclusive de monetización de la vida social rural son decisivos y constituyen uno de los caracteres más originales de esta sociedad rural. Es probable, entonces, que la coacción esté orientada a tratar de cerrar esta vía potencialmente independiente de existencia social y mercantil. Es probable, a su vez, que la situación bonaerense difiera de la correntina donde la institución del poblador se enmarca dentro de relaciones de trabajo en las cuales la coacción apunta a superar la crisis abierta por la revolución. ${ }^{39}$

Góngora, entonces, pudo haber confundido los efectos con las causas pero en otros aspectos sus observaciones son muy sutiles: "las tenencias rurales, desde el préstamo al inquilinaje, nada tienen que ver con la encomienda ni con las instituciones de la Conquista. Proceden del segundo momento de la historia colonial, en que se estratifican, hacia arriba, los terratenientes, hacia abajo los españoles pobres y los diversos tipos de mestizajes y castas. Los tenedores de tierras son hombres sueltos libres de tributo y de toda fijación local. La estratificación se marca

38 E. VAN YOUNG, " Sectores medios rurales en el México de los Borbones. El interior de Guadalajara en el siglo XVIII", en HISLA, VIII, Lima, 1986, pp. 102-103.

39 J.C. CHIARAMONTE, Mercaderes del Litoral. Economía y sociedad en la provincia de Corrientes, primera mitad del siglo XIX, Buenos Aires, FCE, 1991, pp. 114-117. 
crecientemente en los siglos XVIII y XIX, y en la misma proporción se agravan los deberes de los inquilinos. El tránsito de la ocupación pastoril del suelo a la agricultura cerealista coincide con el mismo proceso y lo origina en parte".

Aquí el arrendamiento en cualquiera de sus modalidades aparece paralelamente a otros dos fenómenos (el mestizaje y la movilidad de la población, por un lado) y al predominio de la explotación agrícola sobre la ganadera.

\section{b) Una comparación de las prácticas y las normas de arrendamiento.}

Ahora bien. Como se vio, la mayor parte de las interpretaciones tienen fuertes rasgos en común: en general se plantean en términos de relaciones exclusivamente estructurales y cuando introducen el accionar de los grupos sociales en ellas to hacen remitiendo casi exclusivamente a las estrategias de las clases terratenientes. Ello -muy evidente en el planteo de Halperín, Larson o Kay- deja de lado dos problemas claves: las estrategias y acciones de los pobladores y el hecho que varias de estas clases terratenientes están en pleno proceso de formación; no es casual que el autor que lo ha tomado en cuenta -Salazar- haya venido a revisar muchas de las explicaciones aceptadas.

Si la atención se concentra en las prácticas sociales efectivamente observables es interesante registrar las homologías que aparecen. No es ésta la ocasión de efectuar un catálogo completo pero conviene retener que ya Góngora se topó con ellas al rastrear su comparación en base a fuentes jesuitas. Así encontró que el cánon de arriendo suele ser fijado en base a la superficie sembrada, en contratos verbales anuales que se renuevan automáticamente y que era frecuente que se adeudaran arriendos en condiciones tales que la "liberalidad patriarcal" de los jesuitas estaba atenta a los años de malas cosechas. Estas prácticas no eran demasiado diferentes de las de Buenos Aires y, en especial, en las tierras que habian pertenecido a los jesuitas. ${ }^{40}$ El hecho más significativo es que un conjunto de prácticas comunes pueden reconocerse a lo largo y a lo ancho de la América española. Por ejemplo -además de las recién señaladas- es común encontrar la condonación de esas deudas en condiciones de escasez, la existencia de arriendos laxos o

40 Cf. nuestro trabajo "Según la costumbre del pays': costumbre y arriendo en Buenos Aires durante el siglo XVIII", en Boletín del Instituto de Historia Argentina y Americana Dr. Emilio Raviganani, 12, Buenos Aires, 1995, pp. 39-64. 
nominales e inclusive sin canon en tierras subutilizadas o marginales, el carácter verbal y consuetudinario de los convenios y su amplia variabilidad o los derechos de usufructo de otros recursos. ${ }^{41}$ La existencia de estas prácticas y normas comunes debe ser reconsiderada pues permite registrar toda una gama de interrelaciones de las que no puede prescindir un enfoque regional.

Por cierto que hay aquí un elemento decisivo: la mayor parte de la evidencia disponible suele estar construída en base a documentación jesuita 0 de las Temporalidades. Pero aún suponiendo que estas prácticas fueran sólo válidas para sus posesiones, igualmente ya indica uno de los canales básicos de esas interrelaciones. Además, los mejores estudios advierten que la excepción jesuita residía más en la magnitud de sus operaciones y en la racionalidad del manejo de los establecimientos que en las prácticas agrarias que desarrollaban, las que no serían demasiado diferentes de las de la zona en que cada unidad estaba implantada.

Hay, por cierto, otro elemento más obvio que no deja de ser relevante. La abigarrada legislación y jurisprudencia española reconocía el valor de las "costumbres del pays" como fuente de derecho, pero, por su propio carácter, solía codificar prácticas previamente existentes y conferir a disposiciones originalmente fijadas para una región tanto de América como de la península- un valor más general aunque reconociendo siempre el valor normativo de los usos frente a los aspectos no convenidos. Buen testimonio de ello, por ejemplo, fue el conjunto de disposiciones que regulaban el usufructo común de los pastos y los montes. Otro, y ya sí vinculado directamente con el arrendamiento, la práctica de anular el cobro de rentas en situaciones de crisis y escasez que a primera vista parece jesuita- era plenamente aceptada por los jurisconsultos coloniales apoyándose en las Partidas. Lo más importante no es, sin embargo, su existencia normativa sino que era parte del arsenal argumental de los pobladores y efectivamente practicado. De este modo, no creo que el problema pueda reducirse al "transplante" de una estructura jurídica sino que se trata de analizar la compleja construcción de ese conjunto de normas y prácticas sociales en las que -en cada regiónse inscribian las relaciones de arrendamiento.

41 Cf. por ejemplo, Pablo MACERA, Feudalismo colonial americano: el caso de las haciendas peruanas, Lima, 1982, pp.189 y SS; HERMAN W. KONRAD, Una hacienda de los jesuitas en el México colonial: Santa Lucía, 1576-1767, México, FCE, 1989. 
Si una regularidad observada a través de la evidencia comparada es que el arrendamiento aparece difundido en contextos regionales de intensa movilidad poblacional podemos pensar en términos de hipótesis que ella está en la base de la difusión y recreación de prácticas y normas sociales, mucho más en una región como Buenos Aires que está en proceso de estructuración social. Al respecto, importa tener en cuenta que esta movilidad es muy intensa a nivel interregional aunque también abarca migraciones interoceánicas. Hasta ahora ellas han sido poco estudiadas para el siglo XVIII y se ha prestado mucha mayor atención a su impacto sobre las élites y el mundo urbano que sobre el rural. Ahora bien, son varios los casos estudiados que nos muestran la presencia de "españoles" entre los arrendatarios y en Buenos Aires ellos parecieran haber sido parte importante de los productores y arrendatarios de quintas de los alrededores. En plena campaña, aunque su presencia no es posiblemente despreciable, es muy decisiva la presencia de los migrantes internos. Es posible que buena parte de las prácticas y las normas sociales de este amplio conjunto de espacios regionales formen parte de las "costumbres de del pays". Sino, al menos, sustentaron las expectativas y guiaron la acción de una parte de sus pobladores.

\section{Conclusión: por una historia rural y regional comparada.}

Situar el fenómeno del arrendamiento de tierras en Buenos Aires en su contexto adecuado supone evitar una restricción espacial que opaque buena parte de sus componentes. Ante todo, analizar un fenómeno que hace a la conformación de las relaciones sociales en el área obliga, al menos, a considerarlo dentro del conjunto del espacio rioplatense y a no perder de vista el contexto hispanoamericano en el que se inscribe. Es, así, un buen ejemplo, de las posibilidades que puede brindar la historia comparada a los estudios regionales de detalle. Quizás nada mejor que recordar una muy conocida descripción para ejemplificarlo:

"como actualmente sucede, que un solo hacendado tiene doce leguas de circunferencia, no pudiendo trabajar con su familia dos, de que resulta, como lo he visto prácticamente, que alojándose en los términos de su hacienda, una o dos familias cortas se acomodan en unos estrechos ranchos, que fabrican de la mañana a la noche, y una corta ramada para defenderse de los rigores del sol, y preguntándoles por que no hacian casa más cortas y desahogadas, respecto de tener abundantes maderas, respondieron que 
porque no los echasen del sitio o hiciesen pagar un crecido arrendamiento cada año de cuatro a seis pesos, para esta gente inasequible"

Ella nos pone frente varios de los rasgos más comunes y frecuentes de los arrendatarios de la campaña bonaerense de fines del siglo XVIII: pone de manifiesto la presencia de pobladores que no pagan o si lo hacen es por montos "ínfimos", de tenencia muy precaria e inestable que se atestigua bien en el tipo de vivienda. Pero no ha sido redactada por García, Azara, Vieytes o Belgrano. Esta descripción es de Concolocorvo y refiere su visión del campesinado del Tucumán. La traemos a colación para poner claramente de manifiesto el tipo de problemas que afronta una historia rural regional.

Concolocorvo señala que será conveniente obligar "a los hacendados de dilatado territorio a que admitan colonos perpetuos hasta cierto número, con una corta pensión los primeros diez años y que en lo sucesivo paguen alguna cosa más" aunque prefiere seguir el ejemplo de algunas provincias europeas "el que estos colonos pagasen sus censos en las especies que cogiesen de la misma tierra, como trigo maíz y cebada, los labradores; los pastores y criadores de ganado en vacas o novillos, cameros, gallinas, etc". La delimitación de los modos de establecer las rentas que propone introducir en el Tucumán a partir de la experiencia europea es, justamente, el modo que la "costumbre del pays" de Buenos Aires pautaba.

Hay algo más que también es sugerente. Para estos campesinos del Tucumán ("estos colonos, o por mejor decir gauderios", como los llama Concolocorvo) una renta de cuatro a seis pesos es crecida. Estos montos excesivos allí son los frecuentes en Buenos Aires pero -y no parece un detalle- también en México, por ejemplo, en las haciendas jesuitas..$^{42}$ La existencia de estos "precios" hace dudar de considerarlos tales: cuando son fijos se trata de precios muy estables y extremadamente generalizados al menos en las regiones donde había posesiones que fueron de los jesuitas por toda América. Se trata más bien de precios convencionales, regidos más por normas sociales -la costumbre- que por el "mercado". Aún en la mercantilizada vida rural bonaerense todavía existen amplias zonas del espacio social en los cuales las relaciones económicas siguen incrustadas en las

$42 \mathrm{H}$. TOVAR PINzóN, "Elementos constitutivos de la empresa agraria jesuita en la segunda mitad del siglo XVIII en México", en E. FloRESCANo (comp.), Haciendas..., ob.cit., pp.132222. 
relaciones sociales. ${ }^{43} \mathrm{Y}$ no es casual que ello suceda con el arrendamiento dada las incompletas condiciones de apropiación y valorización de la tierra que hemos visto.

Si estoy en lo cierto la originalidad agraria pampeana deberá ser reconsiderada. Digo reconsiderada y no anulada. Con ello me refiero a un punto crucial: el desarrollo actual de los estudios rurales bonaerenses del siglo XVIII y XIX nos obliga para entender nuestro propio objeto a ampliar las perspectivas espaciales y temporales y a reinscribir la historia agraria en su lugar de origen: la historia rural. Pero también a introducir decididamente el método comparativo en la investigación empírica. El caso de la agricultura cerealera bonaerense y del arriendo de tierras en ella da debida cuenta del problema. Ya, hace más de 20 años, Halperín había advertido que por sus técnicas y modalidades de cultivo esta agricultura era una derivación de la del interior. Pese al avance registrado en los estudios agrarios regionales desde entonces es poco, sin embargo, lo que se puede hoy asegurar al respecto: ello testimonia los límites de una historia agraria regional encerrada dentro de su propio marco regional y la urgencia de desarrollar una perspectiva comparada. Los indicios, al respecto, son muy elocuentes.

Por ejemplo, un rasgo de los arriendos bonaerenses es la combinación de diversas modalidades de rentas aún en la misma propiedad y aunque los arrendatarios sean poco numerosos y ello, por cierto, no es un atributo exclusivo de este área. A veces, se trata del pago de un monto anual fijo en fanegas de trigo (generalmente 4), del mismo modo que se pagaban en las antiguas tierras jesuitas de la Banda Oriental. Otras veces, los montos fijos se abonan en dinero. Es esta combinación la que se ha registrado en las posesiones jesuitas de Salta ${ }^{44}$ aunque su importancia aquí parece ser mucho menor que en Buenos Aires; ¿por qué? Sólo una indagación comparada podrá aportar indicios firmes. Esta combinación también ha sido encontrada en el Paraguay donde tiene analogías muy fuertes con Buenos Aires. ${ }^{45}$

${ }^{43}$ Karl POLANYI, El sustento del hombre, Barcelona, Mondadori, 1994.

44 S. MATA DE LóPEZ, "Mano de obra rural en las estancias jesuitas del Colegio de Salta, 1768$1770^{\prime \prime}$, en Carlos MAYO (comp.), La historia agraria del interior. Haciendas jesuíticas de Córdoba y el noroeste, Buenos Aires, CEAL, 1994, p.81.

45 J.C. GARAVAGLIA, Economía..., ob.cit., pp. 205-210. 
Que en cada región el fenómeno adquirió significados específicos queda claro considerando dos casos polares: por un lado, en la puna jujeña el pago de las rentas estaba muy monetizado y se vinculaba directamente con la participación campesina en el circuito de la plata; pero allí también el fenómeno se difunde asociado a intensos procesos migratorios. ${ }^{46}$ Estos procesos abarcaron también a Salta donde la mayor parte de los indígenas provenientes del Alto Perú eran arrenderos y agregados en tierras de españoles, la distinción entre ambos aparece muy marcada pese a que el arrendero debía sumaba al pago de un canon una serie de prestaciones laborales. ${ }^{47}$ Por otro lado, en Santiago del Estero, el campesinado disponía durante el siglo XVIII de diversas medios en usufructo y en el siglo siguiente el proceso de apropiación forzó su conversión en agregados que realizaban prestaciones laborales a cambio de tierras sin que la renta fuera un elemento decisivo. ${ }^{48}$ La generalizada práctica de la agregación en Santiago incluye su desarrollo entre los campesinos indígenas y no es extraño encontrar una buena proporción de santiagueños entre los agregados bonaerenses.

Los indicios sugieren, entonces, pistas relevantes de indagación. Si una serie de trabajos basados en fuentes jesuitas han permitido desarrollar la historia agraria, cabe pensar las posibilidades de un programa de investigaciones en torno a fuentes, problemas y preguntas comunes desde el siglo XVII al XX. En esta ponencia sólo he intentado mostrar una de las potencialidades de la historia comparada: su capacidad para plantear y afinar hipótesis y para poder pensar mejor los problemas. Lo que quiero plantear a la discusión es hasta dónde nuestra historia regional puede seguir fuera de los marcos de la historia comparada como parte integrante de las investigaciones de detalle. Volvamos por un momento a Bloch:

${ }^{46} \mathrm{~V}$. CONTI y D. SANTAMARÍA, "Mecanismos de intercambio en períodos de transición: el caso de los arrendatarios de dos estancias de la Puna jujeña (1813-1819)", en Anuario de Estudios Americanos, LI: 1, Sevilla, 1994, pp. 123-142.

47 S. MATA DE LÓPEz, " Valle de Lerma, valle calchaqui y frontera este: tierra, producción y mano de obra (segunda mitad del siglo XVIII)", en Avances de investigación. Antropología e historia, Salta, 1989, pp.65-98.

48 Silvia PALOMEQUE, "Los esteros de Santiago. Acceso a los recursos y participación mercantil. Santiago del Estero en la primera mitad del siglo XIX", en Data. Revista del Instituto de Estudios Andinos y Amazónicos, 2, 1992, pp. 11-61. 
"Sólo los trabajos que, prudentemente, se limitan a un marco topográfico restringido pueden dar a las soluciones definitivas los necesarios datos de hecho. Pero éstos difícilmente puedan plantear los grandes problemas. Son precisas, para ello, perspectivas más amplias, en la que los relieves fundamentales no corran para nada el riesgo de perderse en la confusa masa de accidentes menudos. Incluso un horizonte que se extienda a una nación entera es a veces insuficiente. ¿Cómo captar en su singularidad, sin una previa mirada sobre francia, los desarrollos particulares de las diversas regiones? A su vez el movimiento francés no toma verdadero sentido más que cuando ha sido ya planteado en el plano europeo. No se trata de asimilar por la fuerza sino, por lo contrario, de distinguir. No se trata de construir, como en el juego de las fotografias superpuestas, una imagen falsamente general, convencional y borrosa, sino de destacar, por contraste, al mismo tiempo que los caracteres comunes, las originalidades"

Por alli es posible que encontremos un camino fructífero para la historia regional. 